\title{
THE OPTIMIZATION OF JELLIFYING AGENT COMPOSITION ON REGENERATION OF IN VITRO OBTAINED POTATO MICROPLANTS
}

\author{
H. M. Shevaha1, M. M. Kyryk², V. M. Hunchak' ${ }^{1}$, T. M. Oliinyk ${ }^{3}$ \\ ${ }^{1}$ Ukrainian Research Station of Plant Quarantine, Institute of Plant Protection, NAAS, \\ Village of Boiany \\ ${ }^{2}$ National University of Life and Environmental Sciences of Ukraine, City of Kyiv \\ ${ }^{3}$ Institut of Potato Planting, NAAS, Urban Settlement of Nemishaieve
}

Results of studies on the optimization of Murashige and Skoog culture medium with modified maize starch for the acceleration of potato plants micropropogation are provided. It has been established that the method modification increases surveillance parameters, promotes active in vitro growth and development of potato springs.

Key words: in vitro, maize starch, potato starch, wheat starch, culture medium.

In modern conditions of agricultural manufacture, potato seed production requires accelerated propagation of the new varieties of seeds based on high category seeds. A large reserve for forming high production seeds the use of in vitro revitalisation of source material and application of the different methods of accelerated propagation. Technology of potato clonal micropropagation based on cultivation of mericlonal plants on digest media in vitro approved oneself in practice. Artificial digest media for in vitro cultivation of plant cells, tissues and organs are multicomponent mixtures containing mineral and organic compounds of different chemical nature. They provide cultivation objects with trophic and physiologically active substances at the background of optimal $\mathrm{pH}$ potential [1; 2].

Most common, dense digest media produced based on agar - a mixture of highmolecular polysaccharides from extracts of several varieties of red algae, consisting of two polysaccharides - agarose and agaropectin, are used in the in vitro culture of potato. It is used for densification of liquid digest media, giving them a jelly-like state. Agar may contain chlorides, sulfates, ions of calcium, magnesium, and ferrum. Concentration of impurities varies depending on the source of sea algae and method of agar production. Purified agars that are well suited for tissue culture of plants are available on the market. Agar is produced abroad, and as for near-abroad countries - in the Baltic States and Russia (only these countries have appropriate raw material resources for its manufacture among all near-abroad countries). Cost of agar imported to Ukraine is very high, and agaroid produced in Ukraine significantly differs from agar by chemical composition and is not suitable for use in the in vitro culture [3; 4].

In world practice, there are studies on replacement of agar by other gelling components, as the cost value of media with agar substitutes is much lower than agarcontaining. According to M. T. Upadishevyi, the use of homopolysaccharides to replace agar provided increase of propagation factor by 1.2-2.3-fold and sprigging by 1.9-6.9-fold [5].

Upon clonal micropropagation of strelitzia (Strelitzia reginae) Brazilian researchers used such jellifying materials as agarose, phytogel (Phytagel). The best results were obtained with phytogel $[6 ; 7]$.

According to the literature sources, the use of DDKamod significantly improved 
plant regeneration in clonal propagation of some vegetable cultures [8]. O. V. Bilynskyi established that agar replacement by DDKamod has a positive effect on the development of regenerant plants due to reduction of their vitrification and stimulates the production of androgen structures and regenerant plants in the in vitro culture of spring barley [9-11].

Given the above, the purpose of our study was to establish the possibility to use starch as jellifying component of media under clonal micropropagation of potato and assess their effect on the parameters of survival rate and development of potato culture in vitro.

Materials and methods. Study on the selection of new jellifying components was performed at the Crop Biotechnology Laboratory of the Ukrainian Scientific Research Station of Plant Quarantine of the Plant Protection Institute of the NAAS during 2015-2016 under sterile conditions according to the commonly accepted methods by Kalinin methodology [12; 13]. Micro-cuttings were cultured on Murashige and Skoog medium [14] based on starches (maize, potato, wheat) with concentration from $50 \mathrm{~g} / \mathrm{L}$ to $150 \mathrm{~g} / \mathrm{L}$. Medium with agar $(8 \mathrm{~g} / \mathrm{L})$ was used as a control. Concentration of starches was measured by experimental method during studies. All digest media were sterilised by autoclaving under pressure of $1 \mathrm{~atm}$. during $15-20 \mathrm{~min}$., the work was carried out in sterile laminar box. Varieties of potato of Ukrainian selection were used: Slovianka, Poliska rozheva. After planting, tube tubes with potato plants were transferred to the culture room and grown at air temperature of $22-24{ }^{\circ} \mathrm{C}$, relative humidity of $60-80 \%$, illumination of $4 \mathrm{klx}$, photoperiod of 16 hours. After regenerants formed 5-6 nodules, they were cut again and repeated the process of regeneration. All experiments were conducted in three repetitions of 20 plants in each. During the course of studies, visual observation of the development of cuttings, period of rhizogenesis (beginning of the formation of roots, day) and biometric measurements of development were performed. Monitoring and processing of experimental data was performed every 1.5 months.

Based on the results of conducted studies, we can conclude that due to the use of maize starch as jellifying agent instead of agar, increase of the quality of clonal potato microplants and cheapening of technology takes place, since standard technology with the use of agar spends $8 \mathrm{~g}$ of agar priced at 9.12 UAH per $1 \mathrm{~L}$ of digest media. Technology that we had developed, provides the possibility to use starch, with a spending of $80 \mathrm{~g}$ of starch priced at $1.16 \mathrm{UAH}$ per $1 \mathrm{~L}$. Thus, there is a five-fold cheapening of the technology through the use of economic scheme of expenses (9.12 UAH/1.6 UAH = 5.6). 